\title{
Use of a novel camera trapping approach to measure small mammal responses to peatland restoration
}

\author{
Nick A. Littlewood ${ }^{1,2}$ (D) Mark H. Hancock ${ }^{3}$ (D) $\cdot$ Scott Newey $^{1}$ (D) $\cdot$ Gorm Shackelford $^{4}$ (I) $\cdot$ Rose Toney ${ }^{5,6}$
}

Received: 4 August 2020 / Revised: 17 December 2020 / Accepted: 22 December 2020 / Published online: 12 January 2021

(C) The Author(s) 2021

\begin{abstract}
Small mammals, such as small rodents (Rodentia: Muroidea) and shrews (Insectivora: Soricidae), present particular challenges in camera trap surveys. Their size is often insufficient to trigger infra-red sensors, whilst resultant images may be of inadequate quality for species identification. The conventional survey method for small mammals, live-trapping, can be both labourintensive and detrimental to animal welfare. Here, we describe a method for using camera traps for monitoring small mammals. We show that by attaching the camera trap to a baited tunnel, fixing a close-focus lens over the camera trap lens, and reducing the flash intensity, pictures or videos can be obtained of sufficient quality for identifying species. We demonstrate the use of the method by comparing occurrences of small mammals in a peatland landscape containing (i) plantation forestry (planted on drained former blanket bog), (ii) ex-forestry areas undergoing bog restoration, and (iii) unmodified blanket bog habitat. Rodents were detected only in forestry and restoration areas, whilst shrews were detected across all habitat. The odds of detecting small mammals were 7.6 times higher on camera traps set in plantation forestry than in unmodified bog, and 3.7 times higher on camera traps in restoration areas than in bog. When absolute abundance estimates are not required, and camera traps are available, this technique provides a low-cost survey method that is labour-efficient and has minimal animal welfare implications.
\end{abstract}

Keywords Blanket bog $\cdot$ Plantation forestry $\cdot$ Rodent $\cdot$ Shrew $\cdot$ Trail camera $\cdot$ Vole

\section{Introduction}

With reduced costs and increased functionality, camera traps have become an increasingly common tool for wildlife

Nick A. Littlewood

nick.littlewood@sruc.ac.uk

1 The James Hutton Institute, Craigiebuckler, Aberdeen AB15 8QH, UK

2 Department of Rural Land Use, SRUC North Faculty, SRUC Aberdeen, Ferguson Building, Craibstone Estate, Bucksburn, Aberdeen AB21 9YA, UK

3 Royal Society for the Protection of Birds (RSPB), Centre for Conservation Science (CfCS), Etive House, Beechwood Park, Inverness IV2 3BW, UK

4 Department of Zoology, University of Cambridge, Downing Street, Cambridge CB2 3EJ, UK

5 North East Scotland Biodiversity Partnership, The James Hutton Institute, Craigiebuckler, Aberdeen AB15 8QH, UK

6 The Mammal Society, 18 St John's Church Road, London E9 6EJ, UK surveillance and monitoring (e.g. Rovero and Zimmerman 2016). Camera traps are especially used for studying mammals, with the order Carnivora comprising by far the largest group within published studies (Agha et al. 2018; McCallum 2013). Despite their importance, in terms of ecosystem function as prey and as consumers with potential to cause economic damage (e.g. Ryszkowski 1975), relatively fewer studies have focussed on small mammals, such as shrews (Eulipotyphla: Soricidae) and small rodents (Rodentia). However, the use of camera traps for monitoring such species has increased steadily in recent years, especially in Australia (e.g. Burns et al. 2018; Campos et al. 2017; DeSa et al. 2012; Dundas et al. 2019; McCleery et al. 2014; Meek et al. 2012; Meek and Vernes 2015; Molyneux et al. 2017; Murphy et al. 2017; Rendall et al. 2014; Smith and Coulson 2012; Taylor et al. 2013; Yang et al. 2018).

Small mammals often occur in high abundance and can have crucial roles in ecosystem functioning, such as by driving predator populations and thus generating cascading effects on other prey species (e.g. Bêty et al. 2002). However, they can be difficult to survey, due to their small size and largely nocturnal behaviour. Thus, our knowledge of their population 
levels and associated trends can be poor (e.g. Mathews et al. 2018). Small mammals provide particular challenges in camera trapping studies. With camera traps set conventionally (e.g. attached to a tree or post, viewing across a trail), small mammals may be too small to reliably trigger the infra-red sensor and, if photographed, may be more difficult to identify in images than are larger animals. A range of techniques has been deployed to increase effectiveness of camera trapping in such situations. In some studies, this simply involves placing camera traps close to the expected location for the animal to appear, such as directly alongside a narrow track (Murphy et al. 2017). Other studies have used bait stations to attract and keep small mammals close to the camera trap to improve picture quality (e.g. Burns et al. 2018; Diete et al. 2017; Meek and Vernes 2015). A particularly ingenious approach involved floating bait stations to record small mammals in an intertidal area (McCleery et al. 2014), whilst other recent innovations have entailed attracting focal species into chambers (Mos and Hofmeester 2020; Soininen et al. 2015).

A technique sometimes used in studies of small mammals has been to mount camera traps above the ground, typically 1.3 to $1.5 \mathrm{~m}$ high, pointing vertically down to view animals from above (e.g. Campos et al. 2017; De Bondi et al. 2010; DeSa et al. 2012; Dundas et al. 2019; Rendall et al. 2014; Smith and Coulson 2012; Taylor et al. 2013; Welbourne et al. 2015; Yang et al. 2018; Zewe et al. 2013). Smith and Coulson (2012) found that such mounting increased detection probabilities of the small marsupial mammals, potoroos (Diprotodontia), and bandicoots (Peramelemorphia), between two- and five-fold compared to horizontally placed camera traps. Most such studies, though, have been in areas where ground vegetation is sparse. Some have involved selection of vegetation-free ground (Taylor et al. 2013), whilst, in others, vegetation was cleared at the camera trap site (Rendall et al. 2014). Comparing the number of mammal detections using vertically mounted camera traps with a live-trapping technique (pitfall trapping) showed that the camera traps recorded small mammals in considerably greater numbers and at lower cost per survey, if the initial cost of equipment purchase is not included in cost calculations (Dundas et al. 2019). However, vertical camera trap placement, or indeed more conventional horizontal placement, might not be suitable in habitats dominated by dense grasses, shrubs, or other low- to medium-height vegetation, which often support small mammal populations at high densities (e.g. Evans et al. 2015). Furthermore, vertical mounting will reduce the camera trap's detection zone and may make it vulnerable to theft or interference, whilst posts used for positioning cameras might be used as perches by predators, thus deterring small mammals. There is, therefore, a need for a technique that is more easily deployed in a wider range of habitats and that is not dependent on the presence of bare ground.

Some traditional techniques for studying small mammals, including live-trapping, footprint tracking tubes, and hair tubes (e.g. Flowerdew et al. 2004; Pocock and Jennings 2006; Shore et al. 1995), exploit small mammals' behaviour of readily entering tunnels. We developed a camera trapping method that, likewise, involves attracting small mammals into baited tunnels. This method results in target animals being much closer to the camera trap than is usually the case with most other camera trapping setups. Bringing the animal close to the camera trap results in larger and clearer photographs or videos of the animal. A low-cost adaptation, similar to that used by Mos and Hofmeester (2020), overcomes the fixed minimum focus distance of most conventional camera traps and, thus, facilitates the obtaining of clear video footage or images. Compared to conventional camera trap placement, bringing small mammals closer to the camera trap is also likely to increase the reliability with which it is triggered (though the magnitude of such an increase is not tested here), and the close-up footage aids species identification.

Here, we describe and demonstrate application of this method to assess differences in occurrences of small mammals, which are important as prey for many generalist predators, between different stages in blanket bog restoration from conifer plantation. Unmodified blanket bog hosts an internationally important bird assemblage, especially of waders (shorebirds: Charadrii) which are negatively impacted by the proximity of conifer plantations (Hancock et al. 2009; Wilson et al. 2014). This 'edge effect' may reflect the forestry plantations providing shelter and resources for generalist predatory birds and mammals (e.g. Avery and Leslie 1990), including greater availability of small mammal prey; this is supported by recent work showing elevated mammalian predator abundance within and close to forestry plantations in an otherwise open blanket bog landscape (Hancock et al. 2020). Thus, we specifically assess whether removing coniferous tree plantations leads to a reduction in occurrences of small mammals, with potential to reduce resources available to these generalist predators. In doing so, we trialled a novel technique for camera trapping small mammals and investigated its ability to detect differences in small mammal occurrence between different treatments.

\section{Materials and methods}

\section{Camera trap modification and settings}

Bushnell Trophy Camera Traps (Bushnell Corporation, KS, USA), model number 119477 , were adapted by attaching a + 4 dioptre close-up camera filter (52-mm diameter) in front of the lens with adhesive putty (Blu Tack $\left.{ }^{\circledR}\right)$. The infra-red flash was covered with a piece of white paper and three layers of thin brown plastic parcel tape to reduce its intensity to reduce the over-illumination that can occur when an animal is close to a camera trap (Fig. 1a). The camera trap was then attached, 
using bungee cords, to the end of a wooden tunnel with the camera trap's infra-red sensor positioned to point horizontally, just above the floor of the tunnel (Fig. 1b). The tunnel had a rectangular cross-section with internal dimensions of $38.5 \mathrm{~cm}$ long, $15 \mathrm{~cm}$ wide, and $13 \mathrm{~cm}$ high. The floor and side walls of the tunnel were made of untreated timber. The roof comprised a piece of clear plastic (Fig. 1c). With the camera trap attached to the wooden tunnel, the floor of the tunnel at the far end from the camera trap came approximately one-third up the camera trap's view (e.g. see Fig. 2), and the distal half of the tunnel (approximately $20-40 \mathrm{~cm}$ from the camera trap) was in focus. The camera trap end of the tunnel was housed within a clear plastic bag, to provide additional waterproofing, with bungee cords attached to hold the bag secure around the tunnel. The distal third of the tunnel from the camera trap was baited with approximately $20 \mathrm{ml}$ of a 2:1 mix of garden bird seed and dried mealworms.

Camera traps were set to record 15-s videos at each trigger, as videos can aid species identification compared to the use of still images (pers. obs.; Taylor et al. 2013). They were set with a 5-min delay before they could be triggered again. The flash unit was set to low power and the camera trap sensitivity to automatic (such that the sensitivity of the infra-red sensor adjusts according to the ambient temperature). Camera traps were each powered by 12 AA lithium batteries. A new set of batteries was installed in each camera trap at the start of the study, and these lasted throughout.

\section{Fieldwork}

Small mammal camera trap tunnels (hereafter simply referred to as 'tunnels') were deployed on, and adjacent to, Forsinard National Nature Reserve in the Flow Country of northern Scotland ( $3^{\circ} 59^{\prime} \mathrm{W} 58^{\circ} 24^{\prime} \mathrm{N}$; https://www.theflowcountry. org.uk/). Extensive restoration of damaged blanket bog has occurred in this area, commencing in 1997, through felling of non-native coniferous trees that were planted mostly in the 1980s and rewetting by blocking drainage ditches that had been ploughed in the peat to facilitate conversation to forestry plantation (e.g. Hancock et al. 2018).

Tunnels were deployed during three periods, referred to as 'sessions', these being between 17 and 23 July, between 4 and 16 August, and between 4 and 10 September 2014. They were set in each of the following three habitat types representing a forest-restoration-bog sequence: remaining conifer plantation forestry that was 27-30 years old at the time of this study, areas undergoing restoration on which trees had been felled between 2 and 17 years previously, unmodified blanket bog. In total, in each habitat, three tunnels were deployed at each of 12 survey locations (total 36 tunnel deployments per habitat, 108 tunnel deployments overall). Survey locations spanned $17 \mathrm{~km}$ between those that were furthest apart. At each survey location, the three tunnels were placed in a straight line, at 30$\mathrm{m}$ intervals, this being referred to as a 'trap set'. Lines were orientated along plough lines in forest and restoration areas
Fig. 1 Small mammal camera trap tunnel setup showing a camera trap with close-focus lens and flash covering, $\mathbf{b}$ position of camera trap when attached to tunnel, and $\mathbf{c}$ an overview of the tunnel with camera trap attached
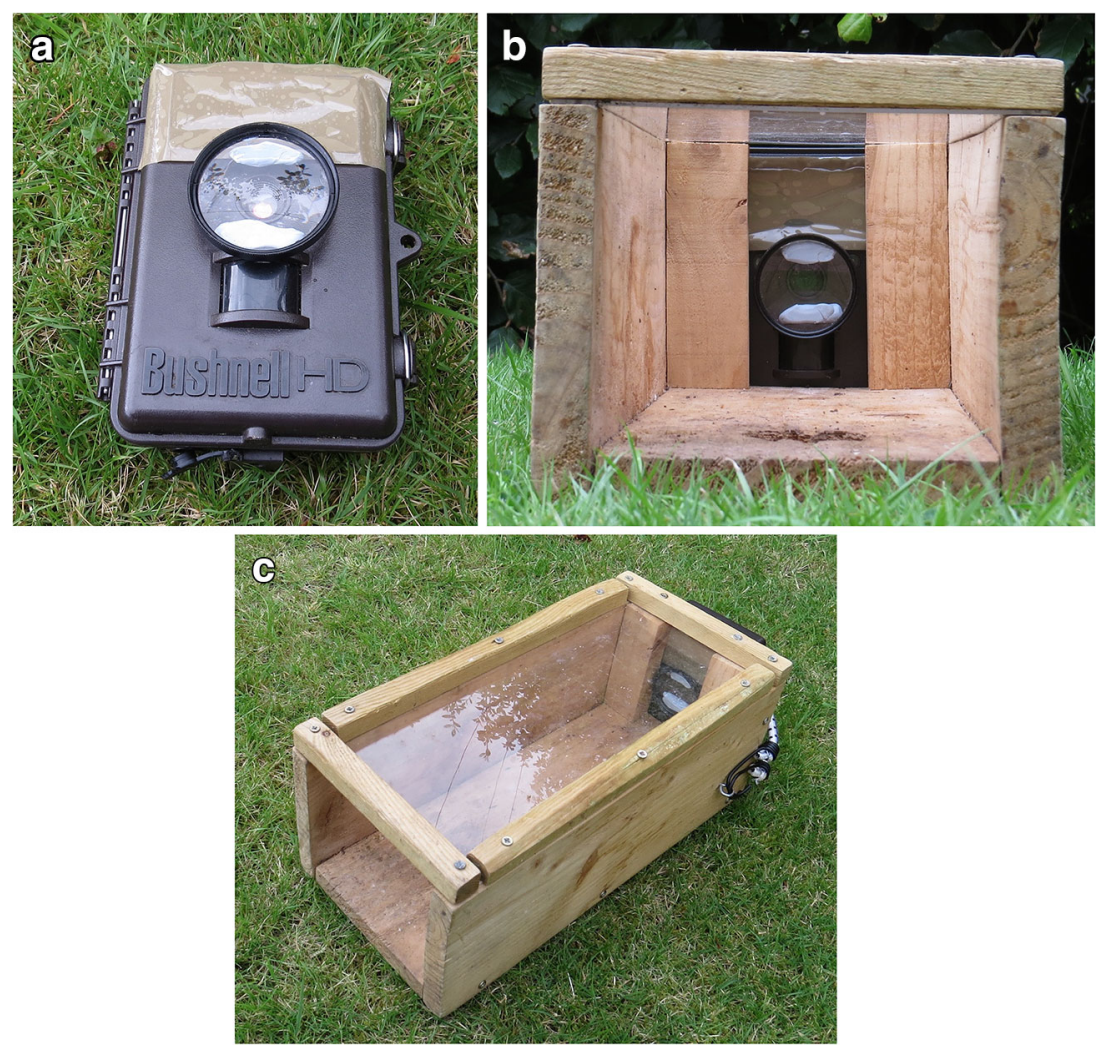

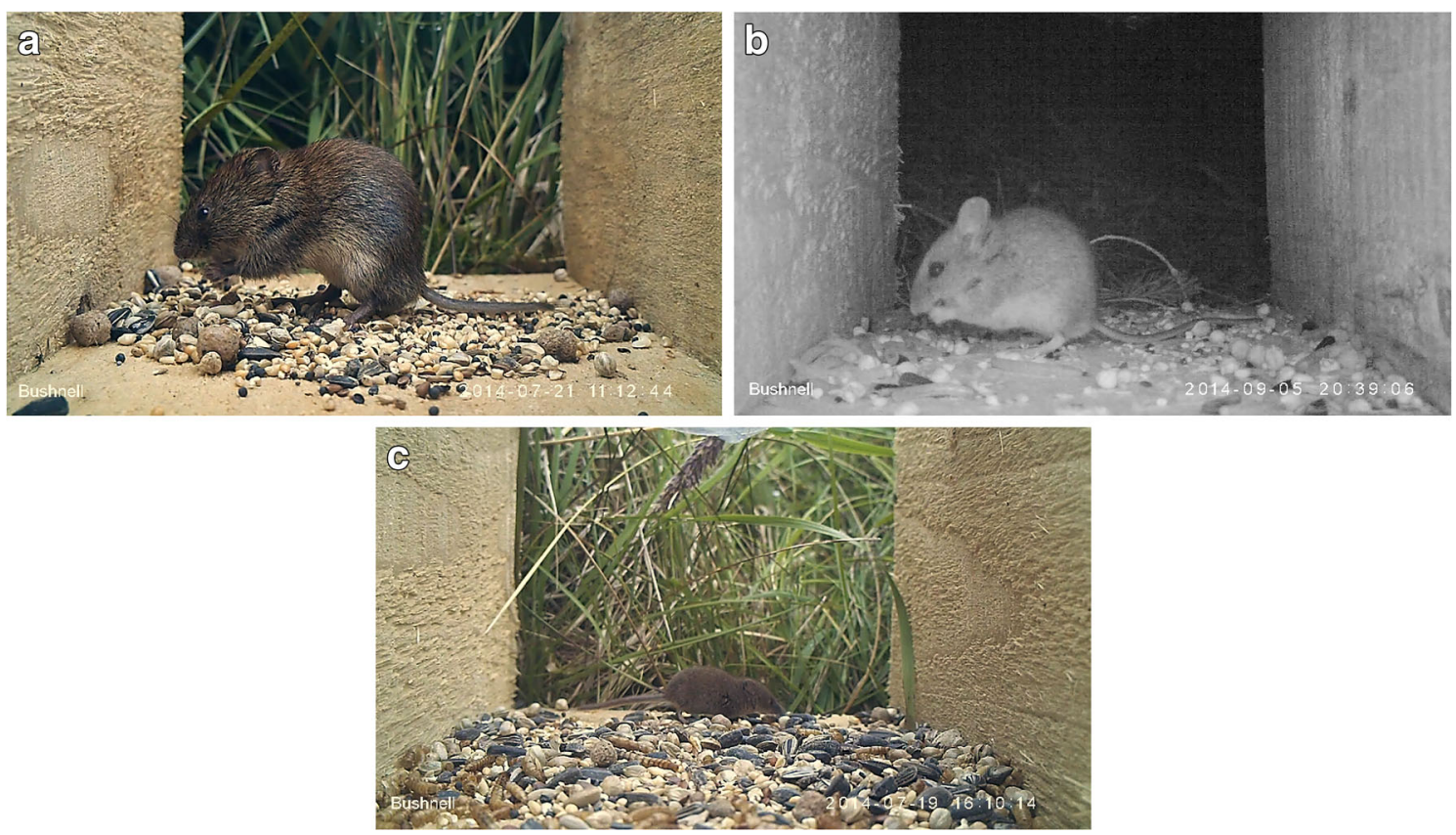

Fig. 2 Example screenshot from video footage. a Bank vole. b Wood mouse. c Pygmy shrew

and were orientated randomly in bog sites. Locations were surveyed in groups of three trap sets (one in each habitat) simultaneously, this being referred to as an 'episode'. Survey locations were selected from a pool of pre-defined locations that were stratified to be spread across the site but with precise locations generated randomly. Generally, survey locations along the same access route were selected for each episode, to minimise travel, though locations surveyed simultaneously were at least $168 \mathrm{~m}$ apart. Thus, nine camera traps (randomly selected for each placement from an overall pool of 11 camera traps) were in use at any one time. Each tunnel was baited, set in position between $3 \mathrm{pm}$ and $9 \mathrm{pm}$, and then retrieved, 2 days later, between $12 \mathrm{pm}$ and $6 \mathrm{pm}$.

\section{Analysis}

Videos were viewed by the first author and assigned to a species. The degree of confidence of the identification, based on features visible in each individual image, was scored as either high or low. Those classed as low confidence were recorded within the categories 'all voles' and 'all shrews', which included also those videos assigned with high confidence to species level. Based on species likely to be present on site, all mice were assumed to be wood mice Apodemus sylvaticus and were thus recorded as high confidence.

The presence or absence of each species, each species group (e.g. 'all voles'), and all species ('any small mammal') was recorded for each tunnel deployment between $10.00 \mathrm{pm}$ on the day of setting and 10.00 am $36 \mathrm{~h}$ later. Thus, any occurrence of a particular taxon on a camera trap during a 36-h trap deployment was recorded as ' 1 ', and nonoccurrence was recorded as ' 0 '.

To analyse the data, we used a generalised linear mixed model, fitted using the GLIMMIX procedure in SAS (SAS 2014). Each row of data represented one trap set, during one episode. The $y$ variable for each taxon was the number of camera traps at that trap set during that episode that had a recorded occurrence of that taxon. We fitted these data in a logistic model, with the number of operational camera traps in the trap set as the binomial denominator (equal to 3 if all camera traps functioned properly). Hence, in effect, we modelled the proportion of camera traps within a trap set that had an occurrence of that taxon. The single fixed explanatory $x$ variable, the variable of interest, was 'Habitat', a three-level factor (forest, restored, or bog). 'Episode' and 'session', coded uniquely, were included as random effects, to account for the potential correlation among observations within each episode, and episodes within each session. Interpretation focussed on the values and differences of the estimated mean occurrence rates for each habitat, and the $P$ value of the 'habitat' effect, where $P<0.05$, was deemed statistically significant.

\section{Results}

All camera traps functioned according to their settings throughout the study with no malfunctions or battery failures. Monitoring covered a total of 108 camera trap deployments (12 trap sets in each of three habitats, with three camera traps deployed for each trap set). Monitoring thus covered a total of 216 camera trap nights and 108 intervening days. Over this 
time, there were 3872 camera trap triggers, with $61 \%$ of these in forest, $33 \%$ in restoration areas, and $6 \%$ in unmodified bog. Of these, 3071 triggers $(79 \%)$ depicted animals. Five small mammal species were recorded, wood mouse, bank vole (Myodes glareolus), field vole (Microtus agrestis), common shrew (Sorex araneus), and pygmy shrew (Sorex minutus). Figure 2 shows example screenshot images taken from the videos. Small mammals were detected on three-quarters of individual camera trap deployments in forest, over threefifths of deployments in restoration areas, and during a third of deployments in unmodified bog (Table 1). Additionally, 21 videos showed only ground beetles (Carabidae), 25 showed a robin (Erithacus rubecula), and a weasel (Mustela nivalis) was detected once in the restoration habitat. Subsequent analysis focusses on the number of camera trap deployments during which each species was detected.

The small mammal species recorded during most individual camera trap deployments was bank vole, followed by common shrew, wood mouse, pygmy shrew, and field vole (Table 1). Statistical analysis of the rate of occurrence for all small mammals combined showed a highly significant difference between habitats $(P=0.0026)$. Small mammals were much more likely to be recorded in forestry, than in bog: the odds of small mammal occurrence were 7.6 times greater in forestry (95\% confidence limits: 2.4-24) than in bog. Occurrence in restoration habitats was also greater than in bogs (odds ratio: $3.7,95 \%$ confidence limits: $1.3-10)$. This pattern was largely driven by the occurrence of rodents, especially bank vole (Table 1), which were not recorded in bog but were frequently recorded in forestry. Random effect estimates suggested that occurrence rates of small mammals at trap sets deployed during the same episode were positively correlated (covariance estimate 1.04; s.e. 0.73 ), but those episodes did not co-vary positively within session (estimated covariance $=0$ ).

Compared to the combined small mammal pattern, a contrasting pattern was recorded for pygmy shrews, for which the occurrence rate was the highest in bog (Table 1). A single species GLMM for this species suggested a near-significant difference between habitats $(P=0.052)$. For this species, odds of occurrence were 15 times greater in bog than in forestry, though this estimate is associated with wide confidence limits (1.6-138). It was not possible to perform a separate analysis for bank vole, or for combined rodents, since there were no occurrences of these species in bog, making it impossible to estimate variance for the bog level of the habitat variable.

\section{Discussion}

Despite the importance of small mammals for ecosystem function, we have a poor understanding of the spatial and temporal distribution of many species at the local scale. A better understanding may help inform management decisions where small mammals are the target of conservation measures, are a pest species, or are an important prey item, such as where they may drive population dynamics of predators. Our study showed marked differences in small mammal occurrence rates between the three surveyed habitats. These differences were due to the dominance of rodents, particularly bank vole, which was predominantly detected within forestry. Rodents were entirely restricted to forestry and restoration plots, where their main foods (large seeds or leafy plant material, e.g. Canova (1993)) are likely to be more available. They were absent from bog plots, where herbaceous cover, especially of grasses, is lower and where waterlogged ground conditions may inhibit opportunities for dry nests or runs. In contrast, shrews, which mostly consume invertebrates, were recorded across all habitats.

Our findings of a far higher overall rate of small mammal occurrences in forestry and restoration plots have important implications for landscape-scale conservation management. Although blanket bog has a naturally species-poor small mammal fauna (e.g. Mazerolle et al. 2001), this study took place within an area that is highly valued for ground-nesting birds, especially waders. Forest proximity can reduce bird breeding abundance for several hundred metres out into bog habitat, likely due to activity of generalist predators (Hancock et al. 2009; Wilson et al. 2014). Forests may sustain generalist predators by providing shelter and supporting a greater diversity and abundance of small mammals. These predators may then prey on ground-nesting birds in bog areas close to forest. Consistent with this, recent work has shown that mammalian predator scat densities in our study area tended to be higher within and near forestry plantations than other areas (Hancock et al. 2020). Previous studies have shown mice and voles to be

Table 1 Number of camera trap deployments in each treatment during which each species or group was detected at least once

\begin{tabular}{llllllllll}
\hline & Bank vole & Field vole & Wood mouse & Common shrew & Pygmy shrew & All voles & All shrews & Any small mammals & Total deployments \\
\hline Forest & 27 & 1 & 11 & 8 & 1 & 27 & 9 & 27 & 36 \\
Restoration & 9 & 1 & 9 & 11 & 8 & 10 & 17 & 22 & 36 \\
Bog & 0 & 0 & 0 & 4 & 10 & 0 & 12 & 12 & 36
\end{tabular}

All figures are from a maximum of 36 deployments in each habitat (three cameras in each of 12 trap sets). The All vole and All shrew columns include those identified to species as well as those identified just at these higher levels. The Any small mammals column combines data from all other categories 
more frequent than shrews in the diets of pine marten Martes martes, red fox Vulpes vulpes, weasel Mustela nivalis, and stoat Mustela erminea (Grabham et al. 2019; Lanszki et al. 2007; McDonald et al. 2000), which are all likely to be important generalist mammalian predators at our field site (Hancock et al. 2020). The absence of rodents on camera trap set in bog indicates that this unmodified habitat is likely to be less suited for sustaining generalist predators. The intermediate occurrence rate of rodents in restoration plots, compared to forestry and bog, suggests that tree-felling and rewetting provide a habitat that is less suitable for these small mammal species, and thus this could reduce resources available to generalist predators. Nonetheless, vegetation recovery may proceed slowly, with grasses being common in some restoration plots even 14 years after tree removal (Hancock et al. 2018), and our results demonstrate that small mammal populations may persist in these plots at levels higher than in unmodified bog for an undetermined period of time. This ties in with findings at the same study site that scat densities of mammalian predators remained higher in restoration areas than in unmodified bog for up to 10 years after tree removal (Hancock et al. 2020).

We are not aware of comparative studies of small mammals in bog restoration projects containing relevant metrics from live-trapping or other methodology with which to compare our camera trap findings. However, comparisons can be made of the ratio of common shrews to pygmy shrews, which is driven partly by diet differentiation. In particular, pygmy shrews eat fewer earthworms than do common shrews (e.g. Pernetta 1976), so they better tolerate wet, acidic sites where earthworms are scarce. Thus, in acid peatland and upland heathland sites across Northern England, Butterfield et al. (1981) found pygmy shrews to be five times more abundant than were common shrews. In unmodified bog plots in our study, we detected pygmy shrews during ten individual camera trap deployments compared to four for common shrews. However, the relationship was reversed in our forest plots, where drier soils may better support earthworm populations, with common shrews detected on eight deployments compared to a single deployment for pygmy shrew. Few data are available on relative abundances of these species in coniferous plantations in the UK, but the greater abundance of common over pygmy shrew is consistent with the pattern in temperate coniferous forest elsewhere in Europe (e.g. Bryja et al. 2002). Thus, the patterns of which of the two shrew species were detected most in forestry and bog in this study (with intermediate figures in restoration locations) are consistent with expectations based on studies elsewhere.

\section{Advantages of small mammal camera trapping}

Comparisons between habitat treatments of the sort described here would more frequently be carried out using live-trapping.
However, live-trapping is logistically demanding and time consuming as it typically involves visiting traps every $12 \mathrm{~h}$ (or at roughly 4-h intervals if shrews might be caught) and involves temporarily removing individuals from their environment with potential welfare implications for the individual and any dependant young. Even when following established guidelines, there may be mortality. One study, for example, reported mortality rates among three different trap types of 3.9 to $13.6 \%$ (Jung 2016). Camera trapping involves no capture of animals, and, therefore, there are minimal animal welfare concerns or requirements to retrieve camera traps within a particular time period. Thus, it is also more suitable than livetrapping if fieldwork is carried out by a less-experienced personnel, including by volunteers, and there is further potential for volunteer involvement in classifying resultant videos or images (e.g. Hsing et al. 2018). Furthermore, if camera traps are already available, the adaptations required incur only modest additional cost. However, unlike camera trapping, livetrapping of small mammals can provide detailed data on species, age, and sex. With individual specific marking combined with appropriate analysis, this can provide precise and accurate estimates of population size and other demographic parameters (Gurnell and Flowerdew 2019).

Other non-capture methods of surveying small mammals each have their own advantages and disadvantages. For example, owl pellet analysis can indicate species presence in the broad area, and basic comparisons of the ratios of abundance of different species between areas or over time may be carried out. However, given the unknown and unquantified way in which owls sample small mammals in a study area, only broad differences at best can be inferred (e.g. between-year differences for established pairs in stable landscape), and the method cannot discriminate between different habitats available in the landscape for owls to hunt over (e.g. Bond et al. 2004). Hair tubes that collect hair or fur samples on sticky pads as an individual passes through a tube can provide finer-scale spatial data at low fieldwork cost, though identification to species level from hairs can be a specialised and time-consuming process (Pocock and Jennings 2006). The method cannot provide additional information such as frequency and timing of visits during deployment. Footprint tunnels, in which small mammals walk over a source of ink within a tunnel and then leave prints on a card (e.g. Muir and Morris 2013), have similar advantages to hair tubes, but species-level identification is difficult and frequently impossible.

Like hair tube and footprint tunnel analyses, camera trapping can provide habitat-specific data, whilst identification to species level is a less-specialised process. Additionally, camera trapping can provide information on daily activity patterns and numbers of individual visits detected, albeit this will be influenced by the presence of bait. Alternative approaches include molecular techniques to detect species presence noninvasively, and these are being increasingly used. Such 
techniques include detecting small quantities of DNA in the environment (eDNA) (e.g. Sales et al. 2020) and non-invasive sampling of genetic material, such as through analysis of faeces (e.g. Ferreira et al. 2018). Similar to camera trapping, there is potential to compare activity levels between sites, based on frequencies of detection among samples taken (e.g. Bohmann et al. 2014). Analysis of samples for genetic material does require input from specialised laboratory facilities, though these techniques might be cost effective in some situations (e.g. Ferreira et al. 2018) and could complement camera trap studies.

We used videos instead of still pictures in this study, as personal observations suggested that these may yield material that better allowed individuals to be identified to species level. Other studies of slightly larger mammals have found little advantage of videos over still images with, for example, Taylor et al. (2013) finding similar detection rates of potoroos, bandicoots, and pademelons (Diprotodontia) with stills and videos and Glen et al. (2013) finding likewise for captive stoats (Carnivora), feral cats (Carnivora), and hedgehogs (Eulipotyphla). However, given the smaller size of our study animals and similarity of some of the species, video may better reveal features that aid identification whilst Villette et al. (2016) also suggested that videos increased the chance of recording a small mammal that is moving about constantly.

\section{Limitations and further work}

Our study was carried out in an area with relatively few small mammal species. Indeed, the lack of any rodent records at all in bog made it impossible to quantify the relative occurrence rate between bog, forestry, and restoration for that group. Of species that are widely distributed in northern Scotland, confusion is most likely between field and bank voles and between common and pygmy shrews. It is important to take account of the potential for uncertainty in species identification, as identification mistakes may be made when interpreting camera trap material of small mammals (Meek et al. 2013). This is especially likely to be an issue in sites where there is a larger pool of potential species present.

All forms of monitoring of small mammals have biases, and some are more suited to certain situations and needs than others (e.g. Flowerdew et al. 2004). Methods of recording small mammals that do not involve capture of animals, such as hair tubes (e.g. Pocock and Jennings 2006), footprint tunnels (e.g. Muir and Morris 2003), and surveys for field signs such as droppings and evidence of feeding (e.g. Lambin et al. 2000), are well suited to remote, low-input monitoring. These usually generate a binary result of detected or not detected, though if multiple stations per site are deployed, comparisons can be made of the number of stations at which species are detected, similarly to the analysis carried out in our study. Such non-capture methods generally do not allow for recognition of individuals that are 'recaptured', and this precludes use of some forms of frequently used analyses, such as capture-mark-recapture (e.g. Castañeda et al. 2018). Similarly, with our camera trapping method, individual identification is not usually possible. However, other studies have found significant relationships between camera trap detection rates and density estimates derived from traditional monitoring methodologies (e.g. Lambert et al. 2017; Villette et al. 2017). Thus, it may be possible that by assessing overall numbers of camera trap detections between sites or over time, one could develop indices that will correlate (but not necessarily linearly) with absolute differences in abundance. Further work to calibrate camera trap detection rates, including use of different camera trap settings, such as the programmed delay following triggers, would be desirable. There may, further, be merit in combining camera trapping with live-trapping and marking, so that recaptures can be based on camera trap detections of marked individuals, whilst comparisons between a range of methods could be highly instructive for informing sampling method selection.

Some recent developments for monitoring small animals have involved incorporating new technical functionality into camera trapping, such as auto-detection of false images (e.g. Nazir et al. 2017), development of new ways of using existing technology such as beam-assisted triggering (Hobbs and Brehme 2017), and altering camera trap hardware to change the focal length (Welbourne et al. 2019). However, our approach is a relatively lower-technology solution that, with adaption, is suitable to be used with a broad range of existing widely used camera traps. Not all camera traps are suited to the application described here. In particular, a minority of commonly used models have the sensor positioned above the lens, and this may result in it aiming too high in close confines of the bait tunnel. However, most camera trap models can be easily attached to the tunnel, sometimes with minor tunnel adaptations to ensure the camera remains aligned and firmly affixed. Later iterations of the technique beyond the study described here have also incorporated drilling a pit around $30 \mathrm{~cm}$ from the camera trap, for placing the bait and, thus, increasing the proportion that is retained in the optimum area for clear focus. With different materials, lightweight collapsible tunnels could be produced, enabling a larger number of units to be transported to remote sampling sites, whilst a bespoke small mammal camera trap, optimised for use with such tunnels, could be developed.

\section{Conclusions}

When indices of small mammal activity are required to either compare between treatments or monitor a site over time, or for site inventory purposes, a modified camera trap tunnel, as described here, can provide a viable alternative to live- 
trapping. It is less labour-intensive than live-trapping and carries minimal mortality risk, and it can be deployed with low-cost materials. Using this technique, we recorded a higher occurrence rate of small mammals and a greater range of species on camera traps set in coniferous forestry planted on bog than in unmodified bog, thus demonstrating greater resource availability for generalist predators. Detections were intermediate in areas undergoing restoration, indicating that tree removal could reduce resources available for generalist predators but that, following tree removal, there may be a time-lag during which small mammal populations remain higher than the naturally low levels of unmodified bog.

Supplementary Information The online version contains supplementary material available at https://doi.org/10.1007/s10344-020-01449-z.

Acknowledgements We would like to thank Fountains Forestry for permission to carry out some of the fieldwork on land that they manage at Forsinard, and the RSPB Forsinard reserve team for supporting this work. We also thank two anonymous reviewers and Paulo C Alves, the handling editor, for comments that significantly improved the manuscript.

Funding NAL was part-funded and SN was fully funded by the Scottish Government's Rural and Environment Science and Analytical Services (RESAS). Camera traps were provided on loan by the North East Scotland Biodiversity Partnership.

\section{Compliance with ethical standards}

Conflict of interest NAL has formerly made and sold tunnels as used in this study. The rest of the authors declare that they have no conflict of interest.

Open Access This article is licensed under a Creative Commons Attribution 4.0 International License, which permits use, sharing, adaptation, distribution and reproduction in any medium or format, as long as you give appropriate credit to the original author(s) and the source, provide a link to the Creative Commons licence, and indicate if changes were made. The images or other third party material in this article are included in the article's Creative Commons licence, unless indicated otherwise in a credit line to the material. If material is not included in the article's Creative Commons licence and your intended use is not permitted by statutory regulation or exceeds the permitted use, you will need to obtain permission directly from the copyright holder. To view a copy of this licence, visit http://creativecommons.org/licenses/by/4.0/.

\section{References}

Agha M, Batter T, Bolas EC, Collins AC, da Rocha DG, MontezaMoreno CM, Preckler-Quisquater S, Sollmann R (2018) A review of wildlife camera trapping trends across Africa. Afr J Ecol 56:694 701. https://doi.org/10.1111/aje.12565

Avery M, Leslie R (1990) Birds and forestry. Poyser, Calton, UK

Bêty J, Gauthier G, Korpimäki E, Giroux J-F (2002) Shared predators and indirect trophic interactions: lemming cycles and arctic-nesting geese. J Anim Ecol 71:88-98. https://doi.org/10.1046/j.0021-8790. 2001.00581.x
Bohmann K, Evans A, Gilbert MTP, Carvalho GR, Creer S, Knapp M, Yu DW, de Bruyn M (2014) Environmental DNA for wildlife biology and biodiversity monitoring. Trends Ecol Evol 29:358-367. https://doi.org/10.1016/j.tree.2014.04.003

Bond G, Burnside NG, Metcalfe DJ, Scott DM, Blamire J (2004) The effects of land-use and landscape structure on barn owl (Tyto alba) breeding success in southern England, U.K. Landsc Ecol 20:555566. https://doi.org/10.1007/s10980-004-5037-7

Bryja J, Heroldová M, Zejda J (2002) Effects of deforestation on structure and diversity of small mammal communities in the Moravskoslezské Beskydy Mts (Czech Republic). Acta Theriol 47:295-306. https://doi.org/10.1007/BF03194148

Burns PA, Parrott ML, Rowe KC, Phillips BL (2018) Identification of threatened rodent species using infrared and white-flash camera traps. Australian Mammalogy 40:188-197. https://doi.org/10. 1071/AM17016

Butterfield J, Coulson JC, Wanless S (1981) Studies on the distribution, food, breeding biology and relative abundance of the pygmy and common shrews (Sorex minutus and S. araneus) in upland areas of Northern England. Journal of the Zoological Society of London 195: 169-180. https://doi.org/10.1111/j.1469-7998.1981.tb03457.x

Campos CM, Velez S, Florencia Miguel M, Papú S, Cona MI (2017) Studying the quantity component of seed dispersal effectiveness from exclosure treatments and camera trapping. Ecology and Evolution 8:5470-5479. https://doi.org/10.1002/ece3.4068

Canova L (1993) Resource partitioning between the bank vole Clethrionomys glareolus and the wood mouse Apodemus sylvaticus in woodland habitats. Italian Journal of Zoology 60:193-199. https://doi.org/10.1080/11250009309355809

Castañeda I, Pisanu B, Díaz M, Rézouki C, Baudry E, Chapuis J-L, Bonnau E (2018) Minimising trapping effort without affecting population density estimations for small mammals. Mamm Biol 93: 144-152. https://doi.org/10.1016/j.mambio.2018.10.004

De Bondi N, White JG, Stevens M, Cooke R (2010) A comparison of the effectiveness of camera trapping and live trapping for sampling terrestrial small-mammal communities. Wildl Res 37:456-465. https:// doi.org/10.1071/WR10046

DeSa MA, Zweig CL, Percival HF, Kitchens WM, Kasbohm JW (2012) Comparison of small-mammal sampling techniques in tidal salt marshes of the Central Gulf Coast of Florida. Southern Naturalist 11:G17-G28. https://doi.org/10.1656/058.011.0109

Diete RL, Meek PD, Dickman CR, Lisle A, Leung LKP (2017) Diel activity patterns of northern Australian small mammals: variation, fixity, and plasticity. J Mammal 98:848-857. https://doi.org/10. 1093/jmammal/gyx003

Dundas SJ, Ruthrof KX, Hardy GESt. J, Fleming PA (2019) Pits or pictures: a comparative study of camera traps and pitfall trapping to survey small mammals and reptiles. Wildl Res 46:104-113. https://doi.org/10.1071/WR18074

Evans DM, Villar N, Littlewood NA, Pakeman RJ, Evans SA, Dennis P, Skartveit J, Redpath SM (2015) The cascading impacts of livestock grazing in upland ecosystems: a 10-year experiment. Ecosphere 6: article 42. https://doi.org/10.1890/ES14-00316.1

Ferreira CM, Sabino-Marques H, Barbosa S, Costa P, Encarnação C, Alpizar-Jara R, Pita R, Beja P, Mira A, Searle JB, Paupério J, Alves PC (2018) Genetic non-invasive sampling (gNIS) as a costeffective tool for monitoring elusive small mammals. Eur J Wildl Res 64:46. https://doi.org/10.1007/s10344-018-1188-8

Flowerdew JR, Shore RF, Poulton SM, Sparks TH (2004) Live trapping to monitor small mammals in Britain. Mammal Rev 34:31-50. https://doi.org/10.1046/j.0305-1838.2003.00025.x

Glen AS, Cockburn S, Nichols M, Ekanayake J, Warburton B (2013) Optimising camera traps for monitoring small mammals. PLoS One 8:e67940. https://doi.org/10.1371/journal.pone.0067940

Grabham AA, Ventress G, Hayward MW (2019) The diet of denning female European pine martens (Martes martes) in Galloway Forest 
District, South West Scotland, Great Britain. Mammal Research 64: 87-97. https://doi.org/10.1007/s13364-018-0398-5

Gurnell J, Flowerdew JR (2019) Live trapping of small mammals, 5th edn. The Mammal Society

Hancock MH, Grant MC, Wilson JD (2009) Associations between distance to forest and spatial and temporal variation in abundance of key peatland breeding bird species. Bird Study 56:53-64. https:// doi.org/10.1080/00063650802648176

Hancock MH, Klein D, Andersen R, Cowie NR (2018) Vegetation response to restoration management of a blanket bog damaged by drainage and afforestation. Appl Veg Sci 21:167-178. https://doi. org/10.1111/avsc. 12367

Hancock MH, Klein D, Cowie NR (2020) Guild-level responses by mammalian predators to afforestation and subsequent restoration in a formerly treeless peatland landscape. Restor Ecol 28:1113-1123. https://doi.org/10.1111/rec.13167

Hobbs MT, Brehme CS (2017) An improved camera trap for amphibians, reptiles, small mammals, and large invertebrates. PLoS ONE 12: e0185026. https://doi.org/10.1371/2Fjournal.pone.0185026

Hsing P-Y, Bradley S, Kent VT, Hill RA, Smith GC, Whittingham MJ, Cokill J, Crawley D, MammalWeb volunteers, Stephens PA (2018) Economical crowdsourcing for camera trap image classification. Remote Sensing in Ecology and Conservation 4:361-374. https:// doi.org/10.1002/rse2.84

Jung TS (2016) Comparative efficacy of Longworth, Sherman, and Ugglan live-traps for capturing small mammals in the Nearctic boreal forest. Mammal Research 61:57-64. https://doi.org/10.1007/ s13364-015-0251-Z

Lambert M, Bellamy F, Budgey R, Callaby R, Coats J, Talling J (2017) Validating activity indices from camera traps for commensal rodents and other wildlife in and around farm buildings. Pest Manag Sci 74: 70-77. https://doi.org/10.1002/ps.4668

Lambin X, Petty SJ, MacKinnon JL (2000) Cyclic dynamics in field vole populations and generalist predation. J Anim Ecol 69:106-118. https://doi.org/10.1046/j.1365-2656.2000.00380.x

Lanszki J, Zalewski A, Horváth G (2007) Comparison of red fox Vulpes vulpes and pine marten Martes martes food habits in a deciduous forest in Hungary. Wildl Biol 13:258-271. https://doi.org/10.2981/ 0909-6396(2007)13[258:CORFVV]2.0.CO;2

Mathews F, Kubasiewicz LM, Gurnell J, Harrower CA, McDonald RA, Shore RF (2018) A review of the population and conservation status of British mammals: technical summary. A report by the Mammal Society under contract to Natural England, Natural Resources Wales and Scottish Natural Heritage. Natural England, Peterborough

Mazerolle MJ, Drolet B, Desrochers A (2001) Small-mammal responses to peat mining of southeastern Canadian bogs. Can J Zool 79:296 302. https://doi.org/10.1139/z00-202

McCallum J (2013) Changing use of camera traps in mammalian research: habitats, taxa and study groups. Mammal Rev 43:196-206. https://doi.org/10.1111/j.1365-2907.2012.00216.x

McCleery RA, Zweig CL, Desa MA, Hunt R, Kitchens WM, Percival HF (2014) A novel method for camera-trapping small mammals. Wildl Soc Bull 38:887-891. https://doi.org/10.1002/wsb.447

McDonald RA, Webbon C, Harris S (2000) The diet of stoats (Mustela erminea) and weasels (Mustela nivalis) in Great Britain. J Zool 252: 363-371. https://doi.org/10.1111/j.1469-7998.2000.tb00631.x

Meek PD, Vernes K (2015) Can camera trapping be used to accurately survey and monitor the Hastings River mouse (Pseudomys oralis)? Australian Mammalogy 38:44-51. https://doi.org/10.1071/ AM15016

Meek PD, Zewe F, Falzon G (2012) Temporal activity patterns of the swamp rat (Rattus lutreolus) and other rodents in North-Eastern New South Wales, Australia. Australian Mammalogy 34:223-233. https://doi.org/10.1071/AM11032
Meek PD, Vernes K, Falzon G (2013) On the reliability of expert identification of small-medium sized mammals from camera trap photos. Wildl Biol Pract 9:1-19. https://doi.org/10.2461/wbp.2013.9.4

Molyneux J, Pavey CR, James AI, Carthew SM (2017) The efficacy of monitoring techniques for detecting small mammals and reptiles in arid environments. Wildl Res 44:534-545. https://doi.org/10.1071/ WR17017

Mos J, Hofmeester TR (2020) The Mostela: an adjusted camera trapping device as a promising non-invasive tool to study and monitor small mustelids. Mammal Research 65:843-853. https://doi.org/10.1007/ s13364-020-00513-y

Muir G, Morris P (2013) How to find and identify mammals. The Mammal Society, UK

Murphy AJ, Goodman SM, Farris ZJ, Karpanty SM, Andrianjakarivelo V, Kelly MJ (2017) Landscape trends in small mammal occupancy in the Makira-Masoala protected areas, northeastern Madagascar. J Mammal 98:272-282. https://doi.org/10.1093/jmammal/gyw168

Nazir S, Newey S, Irvine RJ, Verdicchio F, Davidson P, Fairhurst G, van der Wal R (2017) WiseEye: next generation expandable and programmable camera trap platform for wildlife research. PLoS One 12:e169758. https://doi.org/10.1371/journal.pone.0169758

Pernetta JC (1976) Diets of the shrews Sorex araneus L. and Sorex minutus L. in Wytham grassland. J Anim Ecol 45:899-912. https://doi.org/10.2307/3588

Pocock MJO, Jennings N (2006) Use of hair tunes to survey for shrews: new methods for identification and quantification of abundance. Mammal Rev 36:299-308. https://doi.org/10.1111/j.1365-2907. 2006.00092.x

Rendall AR, Sutherland DR, Cooke R, White J (2014) Camera trapping: a contemporary approach to monitoring invasive rodents in high conservation priority ecosystems. PLoS One 9:e86592. https://doi. org/10.1371/journal.pone.0086592

Rovero F, Zimmerman F (2016) Camera trapping for wildlife research. Pelagic Publishing, Exeter, UK

Ryszkowski L (1975) The ecosystem role of small mammals. Ecol Bull 19:139-145 https://www.jstor.org/stable/20112469

Sales NG, McKenzie MB, Drake J, Harper LR, Browett SS, Coscia I, Wangensteen OS, Baillie C, Bryce E, Dawson DA, Ochu E, Hänfling B, Handley LL, Mariani S, Lambin X, Sutherland C, McDevitt AD (2020) Fishing for mammals: landscape-level monitoring of terrestrial and semi-aquatic communities using eDNA from riverine systems. J Appl Ecol 57:707-716. https://doi.org/10.1111/ 1365-2664.13592

SAS (2014) SAS/STAT version 9. SAS Institute Inc., Cary, North Carolina

Shore RF, Myhill DG, Lhotsky R (1995) Capture success for pygmy and common shrews (Sorex minutus and S. araneus) in Longworth and pitfall traps on upland blanket bog. J Zool 237:657-662. https://doi. org/10.1111/j.1469-7998.1995.tb05022.x

Smith JK, Coulson GA (2012) A comparison of vertical and horizontal camera trap orientations for detection of potoroos and bandicoots. Australian Mammalogy 34:196-201. https://doi.org/10.1071/ AM11034

Soininen EM, Jensvoll I, Killengreen ST, Ims RA (2015) Diel activity patterns of northern Australian small mammals: variation, fixity, and plasticity. J Mammal 98:848-857. https://doi.org/10.1093/ jmammal/gyx003

Taylor BD, Goldingay RL, Lindsay JM (2013) Horizontal or vertical? Camera trap orientations and recording modes for detecting potoroos, bandicoots and pademelons. Australian Mammalogy 36: 60-66. https://doi.org/10.1071/AM13012

Villette P, Krebs CJ, Jung TS, Boonstra R (2016) Can camera trapping provide accurate estimates of small mammal (Myodes rutilus and Peromyscus maniculatus) density in the boreal forest. J Mammal 97: 32-40. https://doi.org/10.1093/jmammal/gyv150 
Villette P, Krebs CJ, Jung TS (2017) Evaluating camera traps as an alternative to live trapping for estimating the density of snowshoe hares (Lepus americanus) and red squirrels (Tamiasciurus hudsonicus). Eur J Wildl Res 63:7. https://doi.org/10.1007/ s10344-016-1064-3

Welbourne DJ, MacGregor C, Paull D, Lindenmayer DB (2015) The effectiveness and cost of camera traps for surveying small reptiles and critical weight range mammals: a comparison with labourintensive complementary methods. Wildl Res 42:414-425. https:// doi.org/10.1071/WR15054

Welbourne DJ, Claridge AW, Paull DJ, Ford F (2019) Improving terrestrial squamate surveys with camera-trap programming and hardware modifications. Animals 9:388. https://doi.org/10.3390/ani9060388

Wilson JD, Anderson R, Bailey S, Chetcuti J, Cowie NR, Hancock MH, Quine CP, Russell N, Stephen L, Thompson DBA (2014) Modelling edge effects of mature forest plantations on peatland waders informs landscape-scale conservation. J Appl Ecol 51:204-213. https://doi. org/10.1111/1365-2664.12173

Yang X, Yan C, Zhao Q, Holyoak M, Fortuna MA, Bascompte J, Jansen PA, Zhang Z (2018) Ecological succession drives the structural change of seed-rodent interaction networks in fragmented forests. For Ecol Manag 419-420:42-50. https://doi.org/10.1016/j.foreco. 2018.03.023

Zewe F, Meek P, Ford H, Vernes K (2013) A vertical bait station for black rats (Rattus rattus) that reduces bait take by a sympatric native rodent. Australian Mammalogy 36:67-73. https://doi.org/10.1071/ AM13010

Publisher's note Springer Nature remains neutral with regard to jurisdictional claims in published maps and institutional affiliations. 